\title{
Possibilities of using solar energy in the processes of cooling external zones of people
}

\author{
Ewelina Dec ${ }^{1, *}$, Robert Sekret $^{2}$ and Bożena Babiarz ${ }^{1}$ \\ ${ }^{1}$ Rzeszow University of Technology, Faculty of Civil Engineering, Environmental Engineering and \\ Architecture, Department of Heat Engineering and Air Conditioning, Aleja Powstańców Warszawy \\ 6, 35-959 Rzeszów \\ ${ }^{2}$ Czestochowa University of Technology, Faculty of Infrastructure and Environment, Institute of \\ Environmental Engineering, Department of District Heating, Heating and Ventilation, st. Brzeźnicka \\ 60 A, 42-200 Częstochowa
}

\begin{abstract}
Meteorological analyzes unambiguously indicate climate warming. An increase in average air temperatures is recorded in both winter and summer. In recent years, an increasing number of hot and very hot days are observed, and the duration of series of days with maximum daily temperature above $30^{\circ} \mathrm{C}$ is also longer. Occurrence of hot weather adversely affects the person staying outside. The ever-increasing requirements related to thermal comfort, enforce the provision of appropriate conditions not only in the rooms, but also in the external zones of people. Cooling the air in outdoor zones using standard air-conditioning systems can be expensive due to the high demand for electricity. Ensuring cooling through the use of renewable energy, such as solar energy, is a key solution to energy and environmental problems. In this article, the technical potential of solar radiation energy was determined based on data from the RzeszowJasionka meteorological station and the possibilities of using solar energy in air cooling systems in external zones were presented.
\end{abstract}

\section{Introduction}

Long-term meteorological observations clearly indicate that the climate is getting warmer. The upward trend is characterized by both average annual and seasonal air temperatures. Extreme phenomena have a significant influence on climatic conditions, whose current increase in the number of occurrences noticeably changes the dynamics of climate features in Poland. Thermal phenomena that are unfavorable to humans include heat wavesor series of days (at least 3 ) with a maximum daily temperature exceeding $30^{\circ} \mathrm{C}[1,2]$. High temperatures during the summer (above $27^{\circ} \mathrm{C}$ ) are burdensome and dangerous to human health, especially for older people and children. Increasingly hot and hot days [3] significantly limit the human being's stay in the open. The ever-increasing requirements related to thermal comfort enforce the provision of appropriate conditions not only in the rooms, but also in the external zones of working people as well as rest, for example: terrace, playground, sports ground or stage. Creating conditions that meet the human thermal and humid requirements in the open air is

*Corresponding author: d313@stud.prz.edu.pl 
much more complicated than in the case of enclosed spaces. When designing an air treatment installation in the external zone, one should take into account above all atmospheric factors, the intensity of which is often variable both in the seasonal and the diurnal dimension. Particular attention should be paid to urban areas with unfavorable external conditions, caused by increased air pollution and the occurrence of the urban heat island effect. The growing requirements as to thermal comfort in the summer, taking into account climate change, however, generate an increase in the demand for cooling energy. However, the increasing environmental awareness among society allows to significantly reduce energy consumption by improving energy efficiency as well as introducing alternative energy technologies. Considering current requirements [4] of limiting the use of natural resources for energy production, many developed and developing countries promote the use of renewable energy to address the problem of limited fossil fuel resources and environmental protection. Energy can be generated using renewable sources such as wind, solar, geothermal, biomass or tidal energy. However, each renewable source has its own determinants, which determine its potential and the possibility of using it in a given location. The precise determination of the potential of the selected source allows you to correctly estimate the amount of energy efficiently acquired using appropriate technologies.

\section{Solar energy}

Solar energy is the most widespread of all renewable energy sources. Its resources vary depending on the season and day, as well as geographical location. The amount of sun energy possible to obtain in a given place is also affected by the degree of cloudiness or air pollution. For this reason, it is justified to perform local measurements specifying the solar energy resources. Conducting this type of research for a solar unit, however, can be a big hurdle for the investor and generate additional construction costs, which is why they are not usually performed individually. In most cases, measurement data obtained by qualified entities are used for this purpose, such as Institute of Meteorology and Water Management National Research Institute (IMGW-PIB) [5], which observes particular climate parameters for a specific location, including solar radiation $[6,7]$.

The measure determining the solar radiation, which was measured at the earliest in the world, since 1883 in Krakow, is insolation. According to the meteorologists [8], this term means the duration of direct solar radiation. The value of insolation is measured by a heliograph and allows approximate estimation of the number of hours in which solar installations can work [9]. The value of insolation can determine the possibilities of using solar energy, as well as determine the profitable life of the solar installation.

In the literature one can find definitions that incorrectly equate the concept of sunshine with insolation. The solar constant determines the density of the solar radiation flux reaching the upper limit of the atmosphere in a unit of time per unit of surface perpendicular to the radiation. The variability of the solar constant results from the position of the Earth in relation to the Sun, as well as from the unequal activity of the Sun itself. Its average value is assumed as $1366 \mathrm{~W} / \mathrm{m}^{2}$ [10]. When passing through successive layers of the Earth's atmosphere, the intensity of radiation changes as a result of various processes of absorption, scattering and reflection. The intensity of solar radiation is the instantaneous value of the solar radiation power density falling directly on a given surface of the Earth in a unit of time. The sum of direct radiation (reaching the surface of the Earth) and scattered radiation is total radiation, and its energy is called insolation [9]. Within Europe, there is a very large variation in the sum of solar radiation, mainly due to the meridional extent of the continent. Annual total radiation totals north of the continent are more than twice smaller than in the south. Taking into account the summer months, these differences are smaller than in the whole year [11]. Some of the radiation reflected by the surface of the 
earth is on average around $4 \%$, but for some types of surface, such as sand, the amount of reflected radiation is much higher. This property of different surfaces is of great importance when a person is in the external zone. During large insolation, being in areas with high solar reflectance (i.e. dry sand, concrete) may cause an unpleasant feeling of heat [11].

In addition to the geographical location, the important factor affecting the amount of direct solar radiation is the clarity of the atmosphere. The local quality of atmospheric air depends to a large extent on the level of use of conventional energy sources. This results in significant air pollution during the combustion of this type of fuels, primarily during the heating period $[4,12]$.

\section{The potential of solar radiation in Rzeszow}

Based on the database provided by the Ministry of Investments and Development [13], the potential of solar radiation energy for the Rzeszow-Jasionka meteorological station, with the geographical coordinates $50^{\circ} 06^{\prime} \mathrm{N} 22^{\circ} 03^{\prime} \mathrm{E}$, was presented. Data from the database of the Institute of Meteorology and Water Management [5] were used to determine typical meteorological years for the analysis and energy simulation of buildings. Climatic parameters for Rzeszow characterizing a typical meteorological year were determined based on source data [5] from the period of thirty years, i.e. from 1971 to 2000 . The potential of solar radiation energy is best determined by solar radiation, ie the sum of the direct intensity of solar radiation on the horizontal surface (Fig. 1). The highest values of sunshine, which occur in Rzeszow, fall on the summer months and coincide with the occurrence of the highest air temperatures. The average monthly amount of direct solar radiation for months from April to August exceeds $35 \mathrm{kWh} / \mathrm{m}^{2}$. The largest potential for solar energy occurs in June, reaching almost $70 \mathrm{kWh} / \mathrm{m}^{2}$. An important element that characterizes the possibility of using solar energy is the instantaneous intensity of solar radiation. Fig. 2 shows the value of instantaneous direct solar radiation intensity on the horizontal surface measured every hour during the day with the highest intensity of solar radiation.

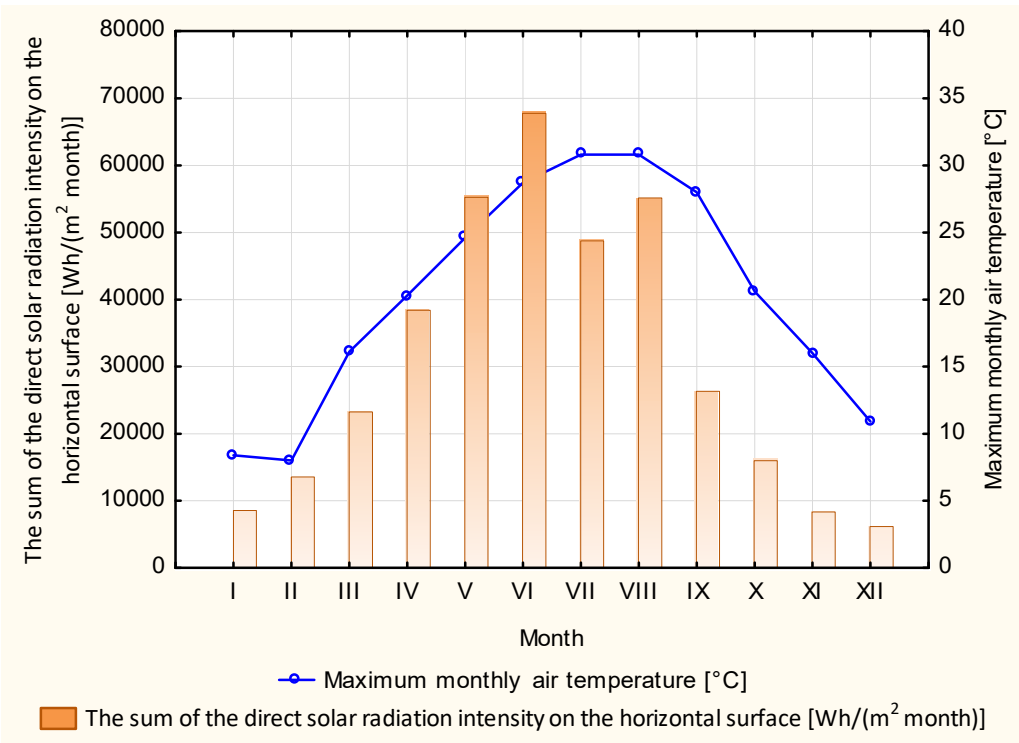

Fig. 1. Average monthly sunshine for a typical meteorological year recorded at the Rzeszow-Jasionka station. 


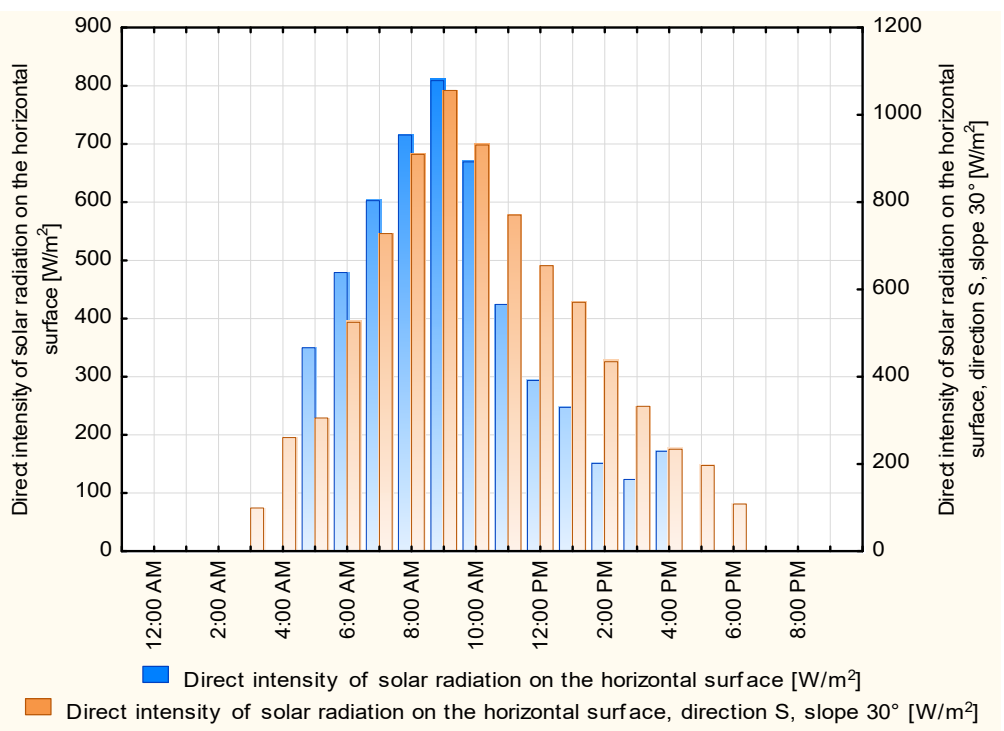

Fig. 2. The value of the direct intensity of solar radiation falling on a horizontal surface and inclined at an angle of $30^{\circ}$ towards the south on June 6 th.

The distribution of instantaneous solar radiation intensity in the daily cycle clearly indicates the highest potential of solar energy in the afternoon hours. The largest solar energy gains will occur with the appropriate orientation of the absorbing surface. The angle of the sun's rays depends on the gauge width and the season. For the geographical location of Rzeszow, as well as for the whole of Poland, the greatest potential of solar radiation occurs in summer, and the largest amount of solar energy is absorbed by the surface inclined at an angle of $30^{\circ}$ towards the south. Differences in the intensity of solar radiation resulting from the angle of inclination of the absorbing surface, analyzed for June 6th, are visible from 10.00 to sunset (Fig. 2). The largest difference in the momentary solar energy yield between these surfaces $\left(361 \mathrm{~W} / \mathrm{m}^{2}\right)$ occurred at 12.00 . The course of the hourly intensity of the sun's radiation shows a similar characteristic to changes in air temperature during the day. Fig. 3 presents the value of the instantaneous solar radiation intensity and the air temperature measured every hour on June 6 th.

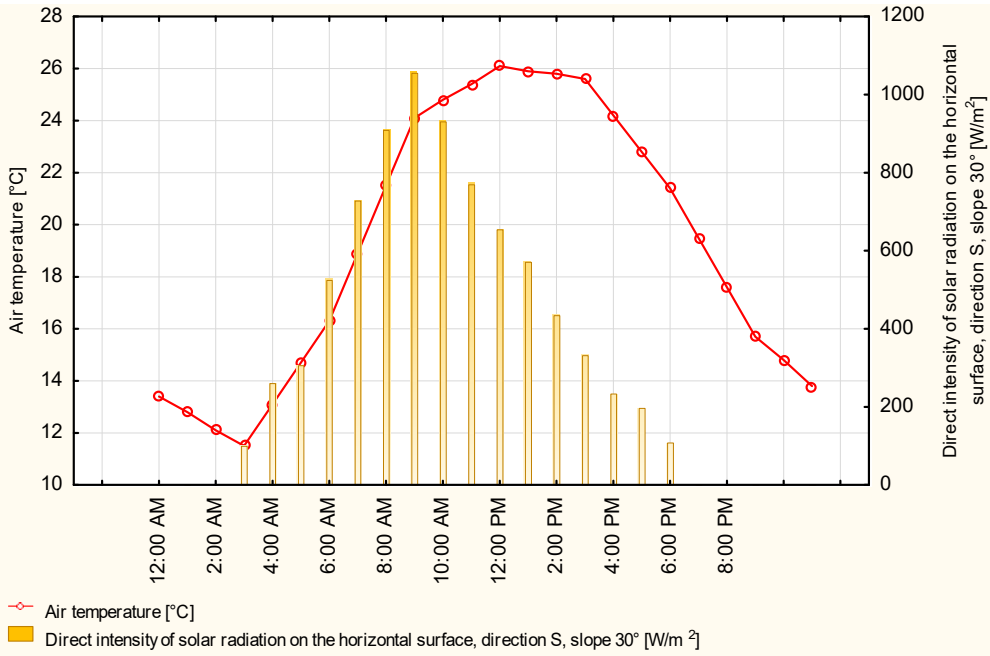

Fig. 3. The value of direct solar radiation intensity and the hourly air temperature on June 6th. 
On the basis of the presented data in Figures 1-3, one should also put forward the thesis that with the increase of solar radiation intensity in the summer period, the demand for cold will also increase. Therefore, the issue of the use of solar radiation energy in the processes of air cooling, especially the external zones of human residence, becomes an important element of scientific work.

\section{Examples of using solar energy for cooling outdoor zones}

In cooling systems, solar energy can be used in the form of electricity or thermal energy. In the first case, photovoltaic cells convert solar energy into electrical energy, which can then be used to drive conventional compressor refrigeration equipment. Thermal energy is produced using solar collectors and used to drive thermochemical or thermo-mechanical devices. There are three basic types of systems in which solar thermal conversion is implemented: closed, open and thermo-mechanical systems [14-16]. In closed systems, the cooling effect is obtained using sorption processes (absorption and adsorption), in open systems the cold is created as a result of changes in air humidity (drying systems), whereas in thermo-mechanical systems the cooling process is carried out using mechanical energy obtained from thermal energy.

Closed systems with absorption devices belong to the most widespread solar systems used for air cooling. The devices used in this system have a wide range of cooling capacities. Their disadvantage is, however, a large decrease in the efficiency and value of the COP cooling efficiency coefficient at lower temperatures of the supply medium. These devices usually achieve a COP cooling coefficient of $0.7-0.8$, with a supply temperature of $80-100^{\circ} \mathrm{C}$. For devices with double absorption effect at the temperature of the supply medium $140-160^{\circ} \mathrm{C}$, a COP of 1.1-1.2 is obtained, and for devices with three-stage evaporation (triple absorption effect) at a supply temperature above $160^{\circ} \mathrm{C}$ COP can be obtained $1.6-1.8[17,18]$. The system with absorption devices requires the use of highly efficient solar collectors, which will be efficient only for a short time at the very peak of the summer season, i.e. in the period when the solar radiation profits are the largest. This means reducing the time of using solar radiation for the needs of air cooling. Nevertheless, taking into account the economic aspect, electricity consumption and environmental impact, solar absorption cooling systems are an increasingly serious alternative to conventional compressor cooling systems [16]. Closed systems with adsorption devices are still less known and used. These systems use the property of a solid adsorption material, which is based on the adsorption of refrigerant vapor on its surface under low pressure conditions, and then the possibility of evaporation of the refrigerant from its structure. In order to maintain the continuity of the process, the adsorber and condenser cooling must alternate with cooling water (at a temperature of about $27-32^{\circ} \mathrm{C}$ ) and regeneration of the adsorber with heating water (temperature $60-80^{\circ} \mathrm{C}$ ), resulting in a cooling water temperature of $8^{\circ} \mathrm{C}$ to $9^{\circ} \mathrm{C}$. Solar collectors can be used for heating the heating medium. At a supply temperature of $60-95^{\circ} \mathrm{C}$, this type of equipment achieves a COP cooling coefficient of $0.6-0.7[18,19]$.

In open systems, cooling occurs as a result of changes in air humidity by means of a sorption device using solid sorbents. In these systems, solar energy is used to regenerate the sorption rotor fill with a stream of heated air, which reduces the moisture content in the air conditioning. The lowering of the temperature of air conditioning is achieved by evaporative cooling in adiabatic humidifiers. In the international nomenclature, they are marked with the SDEC (Solar Desiccant and Evaporative Cooling) symbol. The efficiency of SDEC air conditioning systems depends mainly on the parameters of the air drawn and blown into the human zone. Typically, such systems achieve COP coefficient of the COP efficiency of 0.7 [18], while temporarily they can exceed 1.0. There are also open systems with sorption drying, which use liquid sorbents, generally very similar to the corresponding 
systems using a solid sorbent. The difference lies in the possibility of treating the air directly to the required state of air supply as a result of its contact with a sorption solution with the appropriate concentration $[15,20]$. SDEC systems can cooperate with air or liquid solar collectors. In the case of using air collectors, the regeneration air is directly heated to the necessary temperature in them. Open systems have the ability to store cold, which allows the system to operate also when there is not enough solar radiation. The advantages include a relatively low required temperature for heating the medium before regeneration, amounting to approx. $60-70^{\circ} \mathrm{C}$. As a disadvantage, it is difficult to precisely achieve the desired parameters of the supply air [20,21]. The work [19] describes a review of the existing solutions regarding the use of solar energy in air conditioning systems using sorption dryers.

Solar-powered cooling systems consist of several main components (Fig. 4): solar collectors, buffer tank, heat distribution system, cooling devices driven by thermal energy, optional cold storage battery, air conditioning system (including various forms of cold distribution), auxiliary subsystem (reserve). Subsystem to be located anywhere in the entire system, for example as an auxiliary heater parallel to the solar collector or storage system, or as an auxiliary cooling device [14].

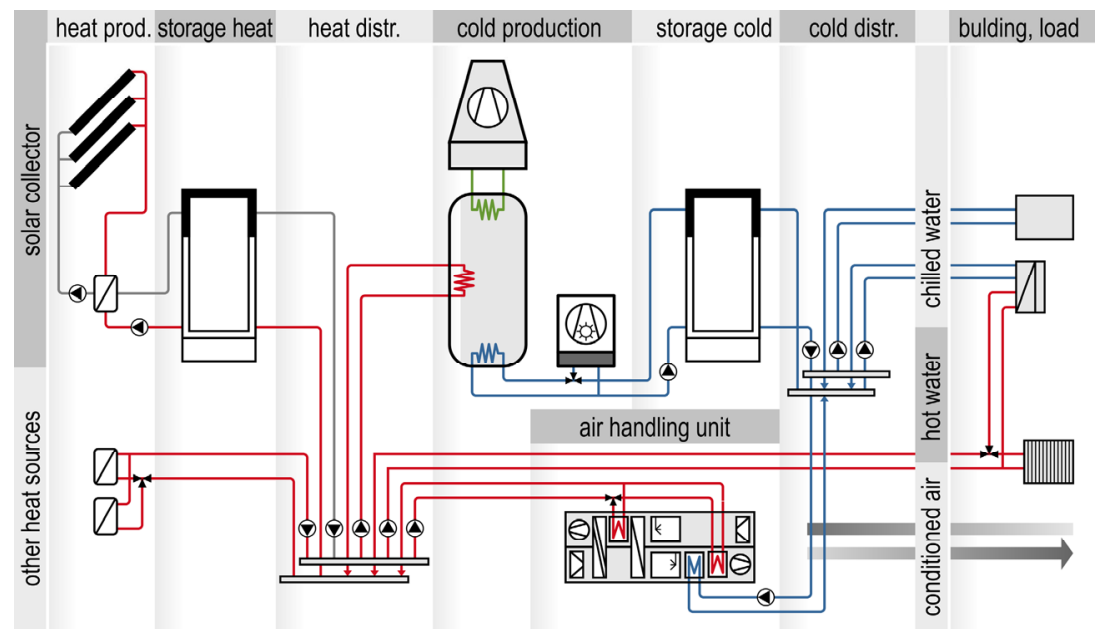

Fig. 4. The general scheme of the solar cooling system, including various variants of cold production [14].

The choice of the solar collector structure depends on the type of cooling system in which it is to be used. In periods when there are no sufficient solar radiation gains, the thermal energy necessary in the proposed cooling systems can be obtained from the integrated heating installation [16]. The paper [18] presents the scope of application of various types of solar collectors in individual cooling systems. Currently, various types of solar collectors are available on the market, and scientific works [22-24] provide opportunities for further increasing the heat output from solar radiation by integrating solar collectors with heat storage. Each type has its thermal characteristics, which determines the efficiency and energy yield in specific climatic conditions. The type of solar collector and their total area should be selected in such a way that the solar energy obtained from them in periods of maximum insolation is able to cover the entire heat demand necessary to achieve the required cooling power.

Thermomechanical systems generate cold generation by using mechanical energy transformed from thermal energy generated in a solar installation. Most of this type of equipment requires high operating parameters: temperature between $120 \div 180^{\circ} \mathrm{C}$ and pressure within the range of $0.1 \div 1.0 \mathrm{MPa}[20]$. 


\section{Summary}

For cooling the air in external zones of human residence, in the climate conditions of Rzeszow, it is possible to apply solar radiation energy. The main role in solar cooling systems is played by solar collectors, in which the energy of solar radiation is converted into useful heat. This heat can be used to supply both absorption and adsorption aggregates as well as regeneration of sorption material in systems with sorption drying. In order to use the solar radiation energy most efficiently, it is necessary to determine its local potential at the stage of planning the solar installation. One should pay attention to the lack of repeatability and irregularity of insolation caused by changing climatic conditions and air pollution. It is worth noting that with the increase of solar radiation intensity in the summer period, the demand for cold will also increase. Therefore, the issue of the use of solar radiation energy in the processes of air cooling, especially the external zones of human residence, becomes an important element of scientific work.

\section{References}

1. K. Błażejczyk, A. Kunert, Bioklimatyczne uwarunkowania turystyki w Polsce (2011)

2. E. Cebulak, D. Limanówka, Dni z ekstremalnymi temperaturami powietrza w Polsce. Wahania klimatu w różnych skalach przestrzennych i czasowych (2007)

3. E. Dec, B. Babiarz, R. Sekret, Analysis of temperature, air humidity and wind conditions for the needs of outdoor thermal comfort (to be published)

4. U. Jakob, WWO, 3 (2006)

5. Instytut Meteorologii i Gospodarki Wodnej, Instytut Meteorologii i Gospodarki Wodnej-Państwowy Instytut Badawczy

6. J. Rudniak, IiOS, 20(3), 371-386 (2017)

7. J. Rudniak, COW, 7, 270-276 (2016)

8. T. Niedźwiedzki, Słownik meteorologiczny, (2003)

9. D. Matuszko, ISES, 2-4, 27-30 (2006)

10. E. Wołoszyn, Meteorologia i klimatologia w zarysie (2009)

11. K. Bhabhor, D. B. Jani, R. J. Dabhi, T. D. Haridwar, Recent Trends in Renewable Energy Application \& Research, February 16-17 (2018)

12. D. Kwiecień, RI, 9, 70-75 (2013)

13. Ministerstwo Inwestycji i Rozwoju, Typowe lata meteorologiczne i statystyczne dane klimatyczne dla obszaru Polski

14. C. A. Balaras, G. Grossman, H-M. Henning, C. A. Infante Ferreira, E. Podesser, L. Wang, E. Wiemken, RENEW SUST ENERG REV, 11, 299-314 (2007)

15. C. A. Balaras, H-M. Henning, E. Wiemken, G. Grossman, ASHRAE J, 48 (6), 14-22 (2006)

16. J. P. Sutikno, S. Aldina, N. Sari, R. Handogo, MATEC Web of Conferences 156 (2018)

17. H-M. Henning, Solar - Assisted Air - Conditioning in buildings, A Handbook for Planners (2004)

18. M. Turski, R. Sekret, Chemical and Process Engin., 37 (2), 293-304 (2016)

19. M. Turski, R. Sekret, Budownictwo i Inżynieria Środowiska, 1, 79-83 (2010)

20. D. Kwiecień, P. Kowalski, RI, 10, 76-82 (2008)

21. R. Sekret, M. Turski, Energy and Build., 51, 15-20 (2012)

22. P. Feliński, R. Sekret, Energy and Build., 152, 558-567 (2017)

23. P. Feliński, R. Sekret, Solar Energy, 144, 758-766 (2017)

24. P. Feliński, R. Sekret, Energy, 114, 1063-1072 (2016) 